\title{
Interaction of Maternal Photoperiod History and Food Type on Growth and Reproductive Development of Laboratory Meadow Voles (Microtus pennsylvanicus)
}

\author{
LESLIE R. MEEK, THERESA M. LEE ${ }^{1}$ AND JILL F. GALLON \\ Department of Psychology, 1103 E. Huron, Neuroscience Lab. Bldg., \\ University of Michigan, Ann Arbor, MI 48104-1687
}

Received 19 April 1994

\begin{abstract}
MEEK, L. R., T. M. LEE AND J. F. GALLON. Interaction of maternal photoperiod history and food type on growth and reproductive development of laboratory meadow voles (Microtus pennsylvanicus). PHYSIOL BEHAV 57(5) 905-911, 1995.The interaction of maternal photoperiod history and four diets were tested by measuring body growth, reproductive development, and pelage development in 9-week-old juvenile meadow voles. Meadow vole dams were housed in long daylengths (LD; $14 \mathrm{~h}$ light/day), short daylengths for 2 weeks (SD; $10 \mathrm{~h}$ light/day), or short daylengths for 26 weeks (PR; photorefractory) prior to mating. Immediately following parturition, one of four diets was available to dams and pups; (a) a control diet containing no 6methoxy-2-benzoxazolinone (6-MBOA); (b) the control diet plus sprouted wheat (which contains 6-MBOA); (c) the control diet plus alfalfa harvested in spring (no 6-MBOA); and (d) the control diet plus alfalfa harvested in autumn (no 6-MBOA). By 9 weeks of age, juvenile meadow voles born to photorefractory dams and fed either spring or fall alfalfa or sprouted wheat were significantly larger and more had achieved puberty than juveniles fed only the control diet. Juveniles born to LD dams demonstrated a smaller increase in developmental rate than photorefractory juveniles when fed alfalfa and spring wheat, and juveniles of SD dams showed the smallest effect of alfalfa and sprouted wheat on development. Supplements of spring wheat and both forms of alfalfa had similar positive effects on growth and reproduction. The authors suggest that juvenile meadow voles rely on the interaction of maternal photoperiod history and the availability of nutrient-rich food such as sprouted wheat and alfalfa to time the onset of growth and puberty.
\end{abstract}

Green food 6-MBOA Meadow voles Puberty Photoperiod Diet Alfalfa Wheat
Photorefractory

SMALL mammals, such as rodents, typically produce young during seasons when environmental conditions are most favorable for survival. For many species, seasonal changes in daylength are used as a cue to determine the timing of breeding onset and/or offset. However, although photoperiodic cues are predictive of future events, yearly fluctuations in environmental conditions exist, suggesting that small rodents should possess the capacity to assess and respond to other environmental cues in addition to changes in the light/dark cycle to determine when breeding should occur. As has been previously suggested (25), animals in unstable environments, especially small rodents that attempt to do all of their breeding during one season, should possess mechanisms to cope with environmental variability so that fitness is maximized. Thus, other environmental factors such as temperature, nutrition, social influences, and variations in genotype should interact with, or in some cases override, photoperiod to influence breeding in some individuals in a rodent population (8).
Meadow voles (Microtus pennsylvanicus) are a small (30-80 g), promiscuously breeding arvicoline species found in North America above $30^{\circ} \mathrm{N}(10)$. This species is strongly photoperiodic, and the somatic and reproductive development of nearly all meadow voles is controlled by photoperiod and the dam's photoperiodic history (14). By 9 weeks of age, meadow vole juveniles born to dams housed in long day lengths mimicking summer (LD; $14 \mathrm{~h}$ light/day) develop a light, short pelage, heavy body weights (males over $40 \mathrm{~g}$; females over $30 \mathrm{~g}$ ), and paired testes weights over $1 \mathrm{~g}$ or uterine weights over $60 \mathrm{mg}$ (15). In contrast, at 9 weeks of age, juveniles born to dams housed in short day lengths mimicking winter (SD; $10 \mathrm{~h} \mathrm{light/day)} \mathrm{develop} \mathrm{a} \mathrm{heavy,}$ thick pelage, lower body weights (males less than $35 \mathrm{~g}$; females less than $30 \mathrm{~g}$ ), and paired testes and uterine weights less than half those seen in LD juveniles (15). At 9 weeks of age, juveniles born to photorefractory dams (PR; dams in SD for 26 weeks prior to mating) have body weights and ovarian weights equivalent to

${ }^{1}$ To whom requests for reprints should be addressed. 
TABLE 1

DIET COMPOSITIONS

\begin{tabular}{llllll}
\hline \multicolumn{1}{c}{ Diet } & Protein & Fat & Carbohydrate & Fiber/Ash & Vitamins/Minerals \\
\hline Purina* 5015 & $17 \%$ & $11 \%$ & $50 \%$ & $9.5 \%$ & $2.5 \%$ \\
6-MBOA free diet & $11.7 \%$ & $2.9 \%$ & $81.1 \%$ & $1.4 \%$ & $2.9 \%$ \\
Alfalfał (second cutting) & $21.7 \%$ & $1.7 \%$ & $50.0 \%$ & $17.6 \%$ & $9 \%$ \\
Sprouted wheat & $13.1 \%$ & $2.9 \%$ & $74.4 \%$ & $9.6 \%$ & $3 \%$ \\
\hline
\end{tabular}

* Neither Purina 5015 nor Dyets \#690001 with Vitamin Mix 300000 contain alfalfa or any "green" food. Purina's primary components: ground wheat, soybean meal, ground yellow corn, dried whey, wheatgerm meal, brewer's dried yeast, animal fat preserved with BHA, soybean oil, and vitamin and mineral mix.

$\dagger$ Dyets 6-MBOA-free food (\#690001) contains: ground wheat, ground corn, ground rolled oats, and vitamin and mineral mix (\#300000).

$\$$ Values for diet composition of alfalfa and wheat were provided from an analysis of sprouted wheat and alfalfa by Litchfield Analytical Services, Litchfield, MI.

those in LD pups', and testicular weights and pelage are intermediate between those seen in LD and SD pups (15). Reproductive maturity as measured by spermatogenic index of PR males is equivalent to that of LD males at 9 weeks (15).

Because meadow voles are short-lived and inhabit northern latitudes in which conditions can vary widely from year to year $(20,24)$, at least some members of this species should behave as facultative breeders (25). That is, when conditions can support gestation and lactation, meadow voles should ignore the inhibitory effects of short daylengths and become reproductively active in response to other environmental cues. One cue important for the onset of reproductive competence is contained in new vegetation, which emerges in the spring; this cue may fine-tune the photoperiod-controlled onset of reproduction (25). This suggestion is supported by the finding that the onset of plant growth varies from year to year in the Colorado Rocky Mountains, and that the onset of reproduction in red-backed voles (Clethrionomys gapperi) parallels that of the plant growth (20).

One vegetative cue that is correlated with the onset of reproduction is 6-methoxy-2-benzoxazolinone (6-MBOA), a chemical produced by fresh, green, growing grasses and sedges in response to tissue injury (30). The addition of 6-MBOA in the form of sprouted wheat to the diet of laboratory montane voles (Microtus montanus), caused increases in uterine weight, the number of developing follicles, the number of litters produced, and the number of young surviving $(3,22,28)$. In addition, in field populations, all $M$. montanus females receiving supplements of fresh wheat grass or 6-MBOA-coated oats in winter were found to be pregnant $(4,23)$. Subsequently, other species of voles $(M$. pinetorum, $M$. townsendii, and $M$. ochrogaster) have also demonstrated reproductive responses to 6-MBOA $(12,26,31)$.

Green foods other than those containing 6-MBOA (alfalfa, spinach, and lettuce) also hasten reproductive development in arvicoline rodents $(3,18,22,28,29)$. Thus, it appears that other aspects of green food, such as nutrient or caloric content, may also interact with environmental variables such as photoperiod or temperature to determine breeding onset in small mammals. Meadow voles, like other small rodents, probably use some aspect of green food to determine the exact timing of the initiation of spring breeding, despite their strong photoperiodic responses. However, to date, no study has examined the effects of 6-MBOA or green plant nutrients on the timing of puberty onset in meadow voles.

The study reported here investigated the effects of sprouted wheat (a grass containing 6-MBOA; (2)) and spring and fall alfalfa (green foods containing no 6-MBOA; (2)) that voles find highly palatable $(18,33)$ on reproductive development in juvenile meadow voles born to dams with different photoperiod histories, to determine the effect of diet on pubertal development.

\section{METHODS}

Animals

The laboratory $M$. pennsylvanicus population used in this experiment is derived from wild stock obtained from Northwestern Pennsylvania $\left(40^{\circ} \mathrm{N}\right)$ and maintained as an outbred population (no sibling or first cousin matings). Subject animals were born to dams treated as follows before mating: One group of dams (LD) was housed in long day lengths (LD; $14 \mathrm{~h} \mathrm{light/day)} \mathrm{for} 10$ weeks after birth and then paired with a male; a second group was housed in LD for 8 weeks after birth and moved to short day lengths (SD; $10 \mathrm{~h}$ light/day) for two weeks before pairing; and a third group was housed in LD for 3 weeks after birth and moved to SD for 26 weeks until photorefractory (PR) and then paired (14).

Adult females (10-29 weeks of age) were paired with sexually experienced adult males for 2 weeks. Dams and litters remained in the birth photoperiod throughout the pups' postnatal development. Room temperature was maintained at $21 \pm 2^{\circ} \mathrm{C}$. Tap water was available ad lib throughout the experiment. Dams had access to Purina diet \#5015 ad lib until pups were born.

\section{Materials}

Spring and fall alfalfa were collected fresh from local fields, bagged, and frozen immediately at $-20^{\circ} \mathrm{F}$. Wheat was sprouted on wet brown paper in the laboratory to a height of $10 \mathrm{~cm}$. Sprouted wheat not used immediately was frozen at $-20^{\circ} \mathrm{F}$. The 6-MBOA-free control diet (Dyets, Inc., Table 1) was ordered in small batches and frozen to maintain freshness and retard spoilage. This same diet has been used successfully in experiments with other arvicoline rodents (26). Based on fat $(9 \mathrm{cal} / \mathrm{g})$, protein ( $4 \mathrm{cal} / \mathrm{g}$ ), and carbohydrate $(4 \mathrm{cal} / \mathrm{g}$ ) content (Table 1$)$, the three diets did not differ significantly from each other in caloric content: the two types of alfalfa had approximately $3.1 \mathrm{cal} / \mathrm{g}$; the sprouted wheat approximately $3.7 \mathrm{cal} / \mathrm{g}$, and the control diet approximately $3.9 \mathrm{cal} / \mathrm{g}$. Approximate caloric values were calculated by multiplying the known percentage in each diet of fat, carbohydrates, and protein by the $\mathrm{cal} / \mathrm{g}$ for each energy source.

\section{Procedure}

On the day of parturition, the Purina chow was removed and LD and SD dams and pups received one of four diets daily: (a) 
ad lib 6-MBOA-free control diet; (b) ad lib control diet plus 3$4 \mathrm{~g}$ sprouted wheat daily/animal; (c) ad lib control diet plus 3$4 \mathrm{~g}$ spring alfalfa daily/animal; or (d) ad lib control diet plus 3$4 \mathrm{~g}$ fall alfalfa daily/animal. The PR dams and pups received diet regimens a-c (no fall alfalfa). Foods were placed inside the cage so that they were accessible to pups as soon as they began consuming solids at 10-12 days of age. After weaning (21 days), pups were maintained in the photoperiod of birth and continued receiving the same experimental diet regimen until autopsied at 9 weeks of age. All green food was consumed daily.

Dams $(N=125)$ and pups $(N=424)$ were weighed weekly and pups were weighed at autopsy $( \pm 0.1 \mathrm{~g})$. Young were individually housed after weaning at 21 days of age. Each group contained 11-28 young of each sex.

At 9 weeks of age a lethal dose of pentobarbital sodium was administered. Hair depth from pelage surface to skin surface on the posterior dorsal surface was measured to the nearest $0.1 \mathrm{~mm}$ (19). Relative hair density was determined by weighing hair shaved from a $1-\mathrm{cm}^{2}$ patch of skin (1). Guard and underhair lengths were measured to the nearest $0.1 \mathrm{~mm}(9,19)$. Nasoanal body length was measured to the nearest $0.1 \mathrm{~mm}$. Testes were removed, weighed, and stored in $10 \%$ formalin, embedded in paraffin, sectioned at $5 \mathrm{~mm}$, and counterstained with hematoxylin and eosin. Spermatogenesis was quantified using a 5-point spermatogenic index (SI) (11). Values ranged from 0 to 5 , with 5 representing complete spermatogenesis and 0 representing the presence of Sertoli cells and spermatogonia only. An SI of 3 or greater is indicative of the presence of mature spermatozoa, and presumably indicates that the male is fertile. Uteri were removed and weighed. Uterine weights exceeding $20 \mathrm{mg}$ indicate that Graafian follicles are developing in ovaries (Lee and Meek, unpublished data).

\section{Statistics}

Males and females differ for all measures except pelage, and sexes were analyzed separately (13). Comparisons of body weight, length, and reproductive development at autopsy were made for each sex with a two-way ANOVA for photoperiod, food type, and photoperiod by food type interactions. Planned contrasts were made with Bonferroni adjusted probabilities using the adjusted error terms from the two-way ANOVAs for each developmental measure. A one-way ANOVA was used to calculate differences in mean pups per litter for each photoperiod at birth and weaning. Chi-square was used to determine significant differences between groups in litter loss, the percentage of male animals with a spermatogenic index indicating fertility (SI > 3.0) and percentage of females with postpubertal uterine weights exceeding $20 \mathrm{mg}$. A value of $p<0.05$ was considered significant. Values are given as mean \pm sem.

\section{RESULTS}

\section{Photoperiod}

Pelage length, depth, and density were influenced only by maternal photoperiod history as reported previously for LD, SD, and PR pups (14). Neither sex nor experimental diets had a significant impact on pelage development.

As previously reported $(13,14)$, maternal photoperiod history significantly influenced the development of body weight, body length, and reproductive systems in males and females $(p<$ 0.001 to $p<0.01$, depending on trait). Overall, LD pups were significantly larger and more LD males and females were postpubertal than were SD or PR pups (Table 2).

\section{Foodtype}

Food also significantly influenced male and female growth and reproductive development $(p<0.001$ to $p<0.05$, depending on trait). Overall, pups fed supplements of wheat or alfalfa were larger and more reproductively developed than pups fed the control diet (Table 2).

\section{Interactions of Photoperiod and Food Type}

Our hypotheses concern the possible differential development of pups within a photoperiod on the different diets; therefore, we report on the effect of the diets within each photoperiod.

\section{Long Day Males}

There were no differences in absolute mean paired testes weights among LD males fed the diet supplements $(p>0.05$; Table 2), but a significantly greater percentage of LD juveniles fed spring alfalfa were fertile (SI $>3$ ) than animals fed either the control diet $(p=0.01)$ or sprouted wheat $(p=0.01$; Fig. $1 \mathrm{~A})$. In contrast to the reproductive advantage gained by those consuming spring alfalfa, LD juveniles fed sprouted wheat were significantly heavier $(p=0.01)$ and longer $(p=0.04)$ than all other LD groups (Table 2). Development of juveniles fed only the control diet was delayed for all measures compared with the supplemented groups ( $p=0.01$; Fig. 1A and Table 2).

\section{Short Day Males}

Juvenile males fed spring alfalfa were significantly heavier than all SD males fed other diets ( $p=0.05$; Table 2$)$, whereas a significantly greater percentage of males fed sprouted wheat were fertile (SI $>3 ; p=0.01$; Fig. 1B). There were no other significant differences among supplemented food groups in SD males. Animals fed the control diet were developmentally delayed on all measures compared with supplemented groups $(p=0.004$; Fig 1B and Table 2).

\section{Photorefractory Males}

There were no developmental differences between groups of males fed either spring alfalfa or sprouted wheat $(p>0.05$; Fig. $1 \mathrm{C}$ and Table 2). Development of males fed only the control diet was delayed for all measures compared with the supplemented groups ( $p=0.01$; Fig. $1 \mathrm{C}$ and Table 2$)$.

\section{Long Day Females}

Like their male siblings, LD juvenile females fed sprouted wheat were significantly longer $(p=0.01)$ and heavier $(p=0.01)$ than those fed other food groups (Table 2). LD juvenile females fed only the control diet were shorter than all other LD groups $(p=0.02)$ and lighter than LD females fed fall alfalfa $(p=0.003)$ and sprouted wheat $(p=0.01$; Table 2$)$, but were not lighter than females fed spring alfalfa $(p>0.05)$. Mean uterine weight did not differ significantly among groups $(p=0.327,2$-tailed test; Table 2). However, a significantly lower percentage of females fed the control diet had uterine weights $>20 \mathrm{mg}(p=0.01$; Fig. 1D) than did the supplemented groups.

\section{Short Day Females}

There were no differences in body weight, length, uterine weight, or percentage of females with uterine weight $>20 \mathrm{mg}$ among SD juvenile females fed any of the supplemented diets $(p$ $>0.05$; Fig. 1E and Table 2). In contrast, control animals had significantly lower values than all other groups for body length 
TABLE 2

INTERACTION OF PHOTOPERIOD AND FOOD ON DEVELOPMENT

\begin{tabular}{|c|c|c|c|c|}
\hline & Control & Spring Alfalfa & Fall Alfalfa & Sprouted Wheat \\
\hline \multicolumn{5}{|c|}{ Males } \\
\hline LD & $(n=26)$ & $(n=23)$ & $(n=21)$ & $(n=12)$ \\
\hline Weight (g) & $26.1 \pm 1.2 \dagger$ & $32.9 \pm 1.4$ & $35.8 \pm 0.9$ & $45.3 \pm 2.3^{*}$ \\
\hline Length $(\mathrm{cm})$ & $10.8 \pm 1.7 \dagger$ & $11.6 \pm 0.1 \ddagger$ & $12.1 \pm 0.1$ & $12.6 \pm 0.2^{*}$ \\
\hline Testes (mg) & $493.0 \pm 69.0 \dagger$ & $901.0 \pm 49.0$ & $917.0 \pm 54.0$ & $937.0 \pm 89.0$ \\
\hline SD & $(n=11)$ & $(n=14)$ & $(n=20)$ & $(n=17)$ \\
\hline Weight (mg) & $28.4 \pm 1.4 \dagger$ & $37.5 \pm 0.9^{*}$ & $34.6 \pm 0.9$ & $34.1 \pm 1.1$ \\
\hline Length $(\mathrm{cm})$ & $11.1 \pm 0.1 \dagger$ & $12.1 \pm 0.1$ & $11.9 \pm 0.1$ & $11.9 \pm 0.1$ \\
\hline Testes (mg) & $397.0 \pm 64.0 \dagger$ & $737.0 \pm 59.0$ & $605.0 \pm 54.0$ & $662.0 \pm 48.0$ \\
\hline PR & $(n=17)$ & $(n=16)$ & & $(n=18)$ \\
\hline Weight (mg) & $24.6 \pm 1.2 \dagger$ & $34.9 \pm 1.5$ & & $35.2 \pm 1.5$ \\
\hline Length (cm) & $10.9 \pm 0.2 \dagger$ & $12.1 \pm 0.2$ & & $11.9 \pm 0.2$ \\
\hline Testes (mg) & $147.0 \pm 42.0 \dagger$ & $580.0 \pm 68.0$ & & $539.0 \pm 42.0$ \\
\hline \multicolumn{5}{|c|}{ Females } \\
\hline LD & $(n=13)$ & $(n=28)$ & $(n=19)$ & $(n=16)$ \\
\hline Weight (g) & $2.63 \pm 1.3^{\prime \prime}$ & $28.2 \pm 0.9$ & $31.4 \pm 1.68$ & $37.1 \pm 1.4^{*}$ \\
\hline Length $(\mathrm{cm})$ & $10.8 \pm 0.1 \dagger$ & $11.2 \pm 0.1$ & $11.4 \pm 0.2$ & $12.1 \pm 0.1^{*}$ \\
\hline Uterus (mg) & $37.0 \pm 7.0$ & $53.0 \pm 5.0$ & $53.0 \pm 7.0$ & $53.0 \pm 8.0$ \\
\hline $\mathrm{SD}$ & $(n=25)$ & $(n=23)$ & $(n=16)$ & $(n=17)$ \\
\hline Weight (g) & $22.9 \pm 0.6^{\#}$ & $27.4 \pm 0.9$ & $25.1 \pm 0.7$ & $26.2 \pm 1.2$ \\
\hline Length (cm) & $10.5 \pm 0.1 \dagger$ & $11.2 \pm 0.1$ & $10.9 \pm 0.1$ & $11.1 \pm 0.2$ \\
\hline Uterus (mg) & $29.0 \pm 5.0^{*}$ & $45.0 \pm 4.0$ & $42.0 \pm 7.0$ & $47.0 \pm 6.0$ \\
\hline PR & $(n=19)$ & $(n=26)$ & & $(n=27)$ \\
\hline Weight (g) & $21.9 \pm 0.8 \dagger$ & $26.3 \pm 0.7$ & & $28.6 \pm 1.1 *$ \\
\hline Length (cm) & $10.5 \pm 0.1 \dagger$ & $11.2 \pm 0.1$ & & $11.6 \pm 0.1^{*}$ \\
\hline Uterus (mg) & $15.0 \pm 2.0 \dagger$ & $45.0 \pm 4.0$ & & $47.0 \pm 6.0$ \\
\hline
\end{tabular}

LD = Long Day; SD = Short Day; PR = photorefractory.

* = significantly greater than all other groups.

$\dagger=$ significantly less than all other groups.

$\ddagger=$ significantly less than fall alfalfa groups.

$\S=$ significantly greater than spring alfalfa group.

$\|$ = significantly less than fall alfalfa and sprouted wheat groups.

" = significantly less than spring alfalfa and sprouted wheat groups.

$(p=0.009)$ and a lower percentage of females with uterine weight $>20 \mathrm{mg}$ ( $p \leq 0.01$; Fig. 1E; Table 2). Females fed the control diet also had significantly lighter body $(p=0.02)$ and uterine weights $(p=0.01)$ than spring alfalfa and sprouted wheat groups (Table 2).

\section{Photorefractory Females}

Female offspring of photorefractory dams fed sprouted wheat were significantly longer $(p=0.02)$ and heavier $(p=0.05)$ than all other groups (Table 2 ). There were no differences between supplemented food groups for uterine weight or the percentage of females with uterine weights greater than $20 \mathrm{mg}(p>0.05$; Fig. 1F and Table 2). Development of females fed only the control diet was delayed for all measures compared with the supplemented groups ( $p=0.001$; Fig. 1F and Table 2).

\section{Dams and Litter Size}

Mean body weights of dams in all photoperiods were equivalent at parturition. PR litter sizes were significantly larger at birth (mean $=4.61 \pm 0.26$ pups/litter) than SD litters (mean $=$ $3.76 \pm 0.19 \mathrm{pups} / \mathrm{litter}$ ), but LD litter size at birth (mean $=4.1$ $\pm 0.25 \mathrm{pups} /$ litter) did not differ from either PR or SD groups. Litter weights at birth did not differ significantly among groups. At weaning (21 days), litter sizes for all photoperiods were not statistically different $(\mathrm{PR}$ mean $=3.5 \pm 0.234 ; \mathrm{SD}$ mean $=3.2$ \pm 0.161 ; LD mean $=3.8 \pm 0.259 ; p=0.096$ ). Loss of pups occurred almost exclusively between birth and weaning, so that litter sizes at autopsy ( 9 weeks) were equivalent to those at weaning for each food and photoperiod group. We conclude that photoperiod and diet effects on development were not due to litter size or consistent differences in dams' ability to maintain pregnancy or lactation.

\section{DISCUSSION}

The developmental effect of supplemented green foods on 9week-old male and female meadow voles housed in all photoperiods was dramatic. Compared to males and females fed the control diet, animals fed any supplemented diet were bigger, longer, had greater testicular and uterine weights and more were 

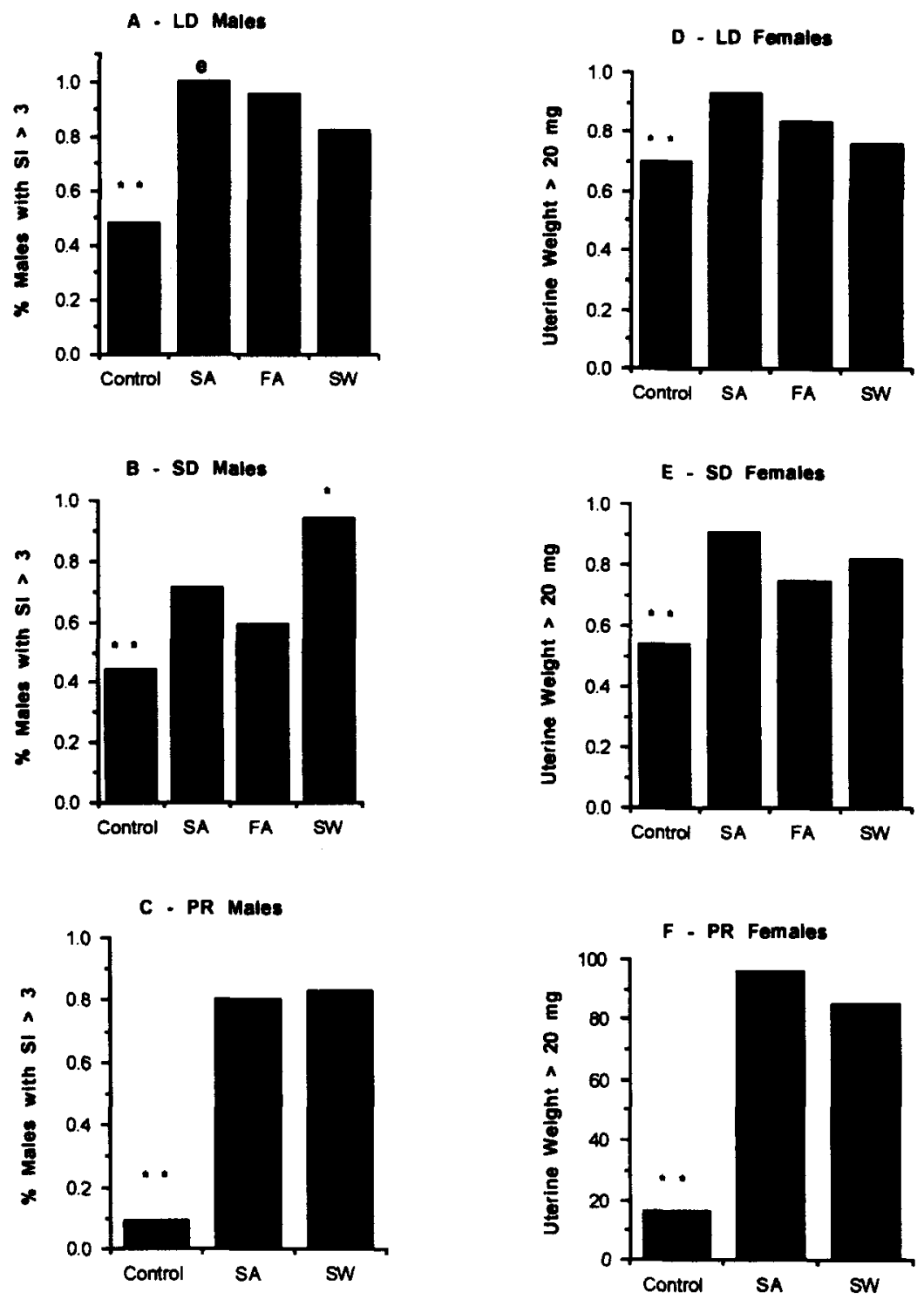

FIG. 1. Comparison of the percentage of long day (A), short day (B), and photorefractory (C) males having a spermatogenic index $>3$ (which indicates the presence of mature spermatozoa) at 9 weeks of age; and comparison of the percentage of long day (D), short day (E), and photorefractory (F) females having a uterine weight $>20 \mathrm{mg}$ at 9 weeks of age. Control $=$ Dyets Inc. 6-MBOA-free diet; $\mathrm{SA}=$ control diet + spring alfalfa; $\mathrm{FA}=$ control diet + fall alfalfa; $S W=$ control diet + sprouted wheat; ${ }^{*}$ significantly greater than all other groups; ** significantly less than all other groups; " $e$ " indicates $\mathrm{SA}$ is significantly greater than control and SW.

fertile as measured by spermatogenic index $(>3)$ and uterine weight ( $>20 \mathrm{mg}$; Fig. 1 and Table 2 ). The effect of the green foods, with some exceptions, was remarkably uniform, with alfalfa and sprouted wheat influencing development similarly within each photoperiod group.

PR males and females fed either sprouted wheat or spring alfalfa supplements demonstrated the greatest gains in measures of reproductive function of any photoperiod group compared with control groups (Fig. 1C and 1F). For example, 83\% of photorefractory males fed sprouted wheat and $80 \%$ fed spring alfalfa had an SI > 3. In comparison, only $9 \%$ of photorefractory males fed the control diet were fertile (Fig. 1C).
Significant increases in reproductive function over control values did occur for $S D$ and $L D$ males and females fed the food supplements (Fig. 1A, 1B, 1D, and 1E). Sprouted wheat was most effective in increasing the reproductive development of SD males (Fig. 1B), and spring alfalfa was most effective in increasing the percentage of LD males with an SI > 3 compared with control values (Fig. 1A). There was no significant advantage of one green food over another in increasing reproductive function in LD, SD, or PR females.

Somewhat surprisingly, LD animals were affected by the addition of green food to the control diet. Both males and females fed sprouted wheat showed increases in body size and length 
compared to animals fed the control diet only. We had expected LD animals to be unaffected by added green food because we thought the control diet would allow growth and development equivalent to that of the Purina diet used in all previous experiments with these animals (Table 1). However, in this experiment both LD and PR pups, but not SD pups, were smaller and less developed when fed the control diet compared with animals from previous experiments fed the Purina chow (13-15).

We also expected to observe a difference in development between LD animals fed spring and fall alfalfa, because it has previously been reported that spring alfalfa accelerated development in field voles (M. arvalis) in comparison to fall alfalfa (18). However, we found that $M$. pennsylvanicus reared in long photoperiods showed no greater increase in growth or development with spring than fall alfalfa (Table 2).

Clearly, as previously hypothesized (25), green foods have an effect on the development of meadow voles. Several studies have demonstrated that the compound 6-MBOA has a strong effect on reproductive development in the montane vole, a species similar in life history and ecology to the meadow vole $(4,22,23,28,30)$. The present study does not support such a selective effect of 6MBOA on meadow voles, because alfalfa and sprouted wheat had very similar effects on development. This was particularly true in SD females, the cohort most often studied in other vole species to document the effects of 6-MBOA $(4,23)$.

If 6-MBOA is not responsible for increasing growth and reproductive development in young meadow voles, it is possible that calories or nutrients contained in all the supplemented foods were responsible. However, none of the diets differed significantly in caloric content, and the diets were also calorically equivalent to the Purina diet normally fed our laboratory animals $(3.7 \mathrm{cal} / \mathrm{g})$. The effects of supplemental alfalfa and sprouted wheat on development may have occurred because these foods added significant amounts of protein to the diet (Table 1). Meadow voles prefer alfalfa and grasses with a high protein content and growth is best with a diet containing $11-24 \%$ protein $(5,6,31)$. The control diet fed in this experiment contained minimal protein $(11.7 \%)$, unless alfalfa or wheat were added (Table 1). This hypotheseis is also supported by the evidence that only when the low protein control diet was supplemented with wheat or alfalfa, did LD and PR pups demonstrate development typically seen with Purina chow. Because Purina chow contains no alfalfa or 6-MBOA-containing food sources, the pattern of growth typically reported for pups in these three photoperiods $(14,15)$ is not likely a response to critical chemicals, but rather the interaction of of maternal photoperiod history and the higher protein food on growth rate.

It is also possible that 6-MBOA and nutrients such as protein interact with specific photoperiod history to exert their effects on development. For example, the addition of sprouted wheat (6MBOA) to the control diet increased body size in LD males and females and reproductive function (SI) in SD males, but the effects of sprouted wheat were equivalent to that of other supplemented foods on other measures of growth and development
(Fig. 1). A recent study with prairie voles demonstrated that prenatal exposure to 6-MBOA accelerated reproductive development in short-day males (27). Because none of the green foods in this study were available prior to partuition, it remains possible that we would have found an enhanced effect of green foods containing 6-MBOA on reproductive function if it had been fed to the dams prior to birth. In the field, animals born at different seasons may be prepared (by the dam's photoperiod history) to use the nutrient/chemical cues contained in green plants for different purposes. Thus, 6-MBOA may serve to enhance growth in LD animals, but enhance spermatogenesis in SD animals.

Why should offspring of photorefractory dams respond most strongly to the presence of supplemental green food in their diet compared with LD and SD young? We suggest that laboratory offspring born to photorefractory females are equivalent to juveniles in the field born in late winter/early spring (i.e., February-March $(7,16,17,21)$ ). Maternal photoperiodic history has prepared PR juveniles for seasonal unpredictability with relatively thick fur, but they also have the ability to grow rapidly and reach puberty earlier than SD pups (15). However, the timing of the onset of spring conditions favorable for breeding varies from year to year in northern climates (20). In the field, the availability of fresh growing grasses (such as wheat) or alfalfa probably serves as a necessary resource to allow the maternally determined growth and reproductive development to occur in young born in late winter (PR pups) or summer (LD pups). Pups born to photorefractory dams, however, seem more sensitive to food resources as a determinant of development than LD pups, and, in the field, the timing of rapid development may be determined each year by the onset of plant growth supplying a high protein food source.

In summary, the results suggest that the presence of fresh green foods with a high protein content allow rapid growth and development in young meadow voles. However, maternal photoperiod history determines how juveniles develop in response to food resources. Juveniles born to LD or photorefractory dams are prepared to develop rapidly and become breeding adults, but a high-protein diet is necessary to allow that rapid development to proceed. For pups born to photorefractory dams, born into an unpredictable and variable season, the nutrients found in fresh green food may act as the proximate signal for the onset of puberty. In contrast, pups born to dams housed in short daylengths, which in the northern latitudes inhabited by this species predict unremittingly harsh winters, are prepared to develop slowly but steadily with a low-quality diet, but with the presence of green food they can develop more rapidly.

\section{ACKNOWLEDGEMENTS}

We would like to acknowledge the following people: J. Donner, C. Suchowski, C. Onishak, and A. Moss for their help, and Steve and Becky Schultz for their donation of fresh alfalfa. This research was supported by NICHD Grant HD24575 (TML) and NSF Predoctoral Fellowship (LRM).

\section{REFERENCES}

1. Al-Khateeb, A.; Johnson, E. Seasonal changes of pelage in the vole (Microtus agrestis). II. The effect of daylength. Gen. Comp. Endocrinol. 16:229-235; 1971.

2. Beck, S. D.; Reese, J. C. Interactions between plants and insects. In: Wallace, J. W.; Mansell, R. L., eds. Recent advances in phytochemistry., vol. 10. New York: Plenum Press; 1976:41-92.
3. Berger, P. J.; Negus, N. C. Influence of dietary supplements of fresh lettuce on ovariectomized Microtus montanus. J. Mammal. 55:747$750 ; 1974$.

4. Berger, P. J.; Negus, N. C.; Sanders, E. H.; Gardner, P. D. Chemical triggering of reproduction in Microtus montanus. Science 214:69$70 ; 1981$. 
5. Bergeron, J. M.; Brunet, R.; Jodoin, L. Is space management of female meadow voles (Microtus pennsylvanicus) related to nutritive quality of plants? Oecologia 82:531-536; 1990.

6. Bucyanayandi, J. D.; Bergeron, J. M. Effects of food quality on feeding patterns of meadow voles (Microtus pennsylvanicus) along a community gradient. J. Mammal. 71:390-396; 1990.

7. Christian, J. J. Regulation of annual rhythms of reproduction in temperate small rodents. In: Steinberger, A.; Steinberger, F., eds. Testicular development, structure and function. New York: Raven Press; 1980:367-380.

8. Clarke, J. R. Long and short term changes in gonadal activity of field voles and bank voles. Oikos 29:457-467; 1977.

9. Dark, J.; Zucker, I. Short photoperiods reduce winter energy requirements of the meadow vole, Microtus pennsylvanicus. Physiol. Behav. 31:699-702; 1983.

10. Findley, J. S. Competition as a possible limiting factor in the distribution of Microtus. Ecology 35:418-420; 1954.

11. Grocock, C. A.; Clarke, J. R. Photoperiodic control of testis activity in the vole, Microtus agrestis. J. Reprod. Fertil. 39:337-347; 1974

12. Korn, H.; Taitt, M. J. Initiation of early breeding in a population of Microtus townsendii (Rodentia) with the secondary plant compound 6- MBOA. Oecologia 71:593-596; 1987.

13. Lee, T. M.; Smale, L.; Zucker, I.; Dark, J. Influence of daylength experienced by dams on postnatal development of young meadow voles (Microtus pennsylvanicus). J. Reprod. Fertil. 81:337-342; 1987a.

14. Lee, T. M.; Zucker, I. Vole infant development is influenced perinatally by maternal photoperiodic history. Am. J. Physiol. 255:R831-R838; 1988.

15. Lee, T. M. Development of meadow voles is influenced postnatally by maternal photoperiodic history. Am. J. Physiol. 34:R749-R755; 1993.

16. Linduska, J. P. Winter rodent populations in field-shocked corn. J. Wildl. Manag. 6:353-363; 1942.

17. Madison, D. M.; McShea, W. J. Seasonal changes in reproductive tolerance, spacing, and social organization in meadow voles: A microtine model. Am. Zool. 27:899-908; 1987.

18. Martinet, L.; Meunier, M. Influence des variations saisonnieres de la luzerne sur la croissance, la mortalite et l'establissement de la maturite sexuells chez le campagnol des chams (Microtus arvalis). Ann. Biol. Anim. Biochim. Biophys. 9:451-462; 1969.

19. McClure, P. A.; Porter, W. Development of insulation in neonatal cotton rats (Sigmodon hispidus). Physiol. Zool. 56:18-32; 1983.
20. Merritt, J. F.; Merritt, J. M. Population ecology and energy relationships of Clethrionomys gapperi in a Colorado subalpine forest. J. Mammal. 59:576-598; 1978.

21. Mihok, S. Life history profiles of boreal meadow voles (Microtus pennsylvanicus). In: Merritt, J. F., ed. Winter ecology of small mammals (Special publication of Carnegie Museum of Natural History), vol. 10. Pittsburgh, PA; 1984:91-102.

22. Negus, N. C.; Pinter, A. J. Reproductive responses of Microtus montanus to plants and plant extracts in the diet. J. Mammal. 47:596$601 ; 1966$.

23. Negus, N. C.; Berger, P. J. Experimental triggering of reproduction in a natural population of Microtus montanus. Science 196:1230$1231 ; 1977$.

24. Negus, N. C.; Berger, P. J.; Forslund, L. G. Reproductive strategy of Microtus montanus. J. Mammal. 58:347-353; 1977.

25. Negus, N. C.; Berger, P. J. Mammalian reproductive physiology (adaptive responses to changing environments). In: Genoways, H. H., ed. Current mammalogy. New York: Plenum Press; 1987:149-173.

26. Nelson, R. J. Maternal diet influences reproductive development in male prairie vole offspring. Physiol. Behav. 50:1063-1066; 1991.

27. Nelson, R. J.; Blom, J. M. C. 6-Methoxy-2-benzoxazolinone and photoperiod: Prenatal and postnatal influences on reproductive development in prairie voles (Microtus ochrogaster ochrogater). Can. J. Zool. 71:776-789; 1993.

28. Pinter, A. J.; Negus, N. C. Effects of nutrition and photoperiod on reproductive physiology of Microtus montanus. Am. J. Physiol. 208:633-638; 1965.

29. Rissman, E. F.; Johnston, R. E. Nutritional and social cues influence the onset of puberty in California voles. Physiol. Behav. 36:343$347 ; 1986$.

30. Sanders, E. H.; Gardner, P. D.; Berger, P. J.; Negus, N. C. 6- methoxybenzoxazolinone: A plant derivative that stimulates reproduction in Microtus montanus. Science 214:67-69; 1981.

31. Schadler, M. H.; Butterstein, G. M.; Faulkner, B. J.; Rice, S. C.; Weisinger, L. A. The plant metabolite, 6- methoxybenzoxazolinone, stimulates an increase in secretion of follicle-stimulating hormone and size of reproductive organs in Microtus pinetorum. Biol. Reprod. 38:817-820; 1988 .

32. Shenk, J. S.; Elliot, F. C.; Thomas, J. W. Meadow vole nutrition studies with semisynthetic diets. J. Nutr. 100:1437-1446; 1970.

33. Thompson, D. Q. Food preferences of the meadow vole (Microtus pennsylvanicus) in relation to habitat affinities. Mid. Natural 74:76-86; 1965. 